\title{
Influencing factors and mechanisms involved in the ignition of low-rank coal: Implications for spontaneous combustion
}

\author{
Yueling Zhang ${ }^{1 *}$, Shengyue $\mathrm{Ma}^{1}$, Jing Xiao ${ }^{1}$, Yajun Tian ${ }^{2}$ and Kechang Xie ${ }^{3}$ \\ ${ }^{1}$ MOE Key Laboratory of Resources and Environmental System Optimization, School of Environmental Science and Engineering, North \\ China Electric Power University, 102206, Beijing, China \\ ${ }^{2}$ New Energy Research Center, National Institute of Clean-and-Low-Carbon Energy, 102211, Beijing, China \\ ${ }^{3}$ Key Laboratory of Coal Science and Technology of Ministry of Education and Shanxi Province, Institute of Coal Chemical Engineering, \\ Taiyuan University of Technology, 030024, Shanxi, China
}

\begin{abstract}
Understanding the ignition mechanism of spontaneous combustion is critical for preventing it. In this work, the effects of different test conditions including oxygen concentration, heating rate, oxidation carrier gas flow rate, and sample amount on the ignition temperature were studied with a thermal gravimetric analyzer. Further, the effects of coal properties on the ignition temperature were also investigated using 15 different low-rank coals. A heterogenous ignition model was proposed that small amount of active species is the key material leading to ignition. The heterogenous ignition mechanism well explained the complex effects of test conditions and coal properties on the ignition temperature of low-rank coal. Finally, an empirical formula for predicting the ignition temperature was derived for the rapid assessment of the spontaneous combustion potential.
\end{abstract}

\section{Introduction}

The highly active chemical structure and spontaneous combustion tendency of low-rank coal cause several challenges in its mining, storage, and utilization [1]. several researches have focused on the development of an index for assessing its spontaneous combustion potential, such as absorption of flowing oxygen [2], activation energy of the oxidation reaction [3], adiabatic heating rate [4], characteristic temperatures [5] and indicative gases [6]. Meanwhile, earlier studies [7-9] have indicated that the reaction of the volatiles released from coal with oxygen in the gas-gas phase causes ignition. Some scholars focused on the changes in the active functional groups present in the coal prior to the ignition and suggested that the oxidation of these groups at low temperatures was the main contributor to spontaneous combustion [10]. While the ignition temperature under different test conditions exhibits significant differences, and the known mechanistic knowledge does not adequately illustrate the causes for such variations.

We employed a thermal gravimetric analyzer to simulate the spontaneous combustion conditions. The test conditions including $\mathrm{O}_{2}$ concentration, oxidation carrier gas flow rate, heating rate and sample amount were changed to observe the ignition temperature variation. Furthermore, the ignition temperatures of fifteen low-rank coals were also tested to investigate the influence of coal properties. Considering the attribution of the high chemical reactivity from the low-rank coals, a new heterogenous coal particle model was proposed. A heterogeneous mechanism was established in combination of thermodynamics, chemical kinetics, and heat transfer principals to deeply understand the ignition process of low-rank coal. We finally fitted an empirical formula to predict the ignition temperature using ash content, volatile content, and reduction reactivity of coal.

\section{Experimental section}

\subsection{Sample preparation}

Fifteen typical low-rank coal samples from the Shendong coalfield in Inner Mongolia of China were used, and their proximate and ultimate analyses are presented in Table 1. The coals were ground to particles of size less than $0.2 \mathrm{~mm}$ and dried for $1 \mathrm{~h}$ in an anhydrous nitrogen atmosphere at $100{ }^{\circ} \mathrm{C}$ before testing.

Table1. Proximate and ultimate analysis of 15 low-rank coal samples.

\begin{tabular}{|c|c|c|c|c|c|c|c|c|c|}
\hline \multicolumn{5}{|c|}{ Proximate analysis $(\mathrm{wt} \%)$} & \multicolumn{5}{|c|}{ Ultimate analysis ( $\mathrm{wt} \%$, daf) } \\
\hline Sample & $M(\mathrm{ad})$ & $A(\mathrm{~d})$ & $V$ (daf) & $\mathrm{FC}(\mathrm{daf})$ & $S$ & $C$ & $H$ & $N$ & $O^{*}$ diff \\
\hline BD-8 & 1.12 & 44.03 & 42.35 & 57.65 & 0.54 & 74.22 & 5.57 & 1.21 & 18.46 \\
\hline BET-22 & 6.60 & 5.10 & 31.22 & 68.78 & 0.58 & 82.32 & 4.53 & 0.92 & 11.65 \\
\hline BET-42 & 5.13 & 15.57 & 36.84 & 63.16 & 0.20 & 81.43 & 4.83 & 1.03 & 12.51 \\
\hline
\end{tabular}




\begin{tabular}{llllllllll} 
DLT-52 & 4.89 & 6.42 & 32.54 & 67.46 & 0.59 & 82.29 & 4.59 & 0.92 & 11.61 \\
HYC-4 & 2.01 & 36.72 & 41.62 & 58.38 & 1.33 & 74.24 & 5.37 & 1.11 & 17.95 \\
HYC-6 & 1.98 & 13.34 & 39.19 & 60.81 & 0.78 & 80.10 & 5.01 & 1.47 & 12.64 \\
JJ-31 & 2.80 & 5.67 & 39.35 & 60.65 & 0.54 & 80.39 & 5.18 & 1.14 & 12.75 \\
SSLT-3 & 6.24 & 11.29 & 38.43 & 61.57 & 2.04 & 78.22 & 4.71 & 0.85 & 14.18 \\
SSLT-4 & 6.85 & 10.21 & 35.57 & 64.43 & 1.87 & 77.81 & 4.38 & 0.78 & 15.16 \\
SSLT-5 & 8.68 & 8.62 & 34.85 & 65.15 & 0.70 & 78.11 & 4.28 & 0.78 & 16.13 \\
SW-12 & 6.14 & 7.39 & 28.56 & 71.44 & 0.25 & 82.29 & 3.93 & 0.76 & 12.77 \\
WL1-31 & 4.94 & 34.00 & 39.18 & 60.82 & 0.70 & 75.79 & 4.65 & 0.74 & 18.12 \\
WL1-42 & 4.98 & 15.85 & 36.45 & 63.55 & 1.47 & 77.73 & 4.27 & 0.77 & 15.76 \\
YJL-43 & 4.00 & 9.48 & 35.39 & 64.61 & 0.36 & 83.56 & 4.90 & 1.19 & 9.99 \\
YJL-52 & 2.36 & 10.09 & 35.39 & 64.61 & 0.31 & 81.05 & 4.77 & 1.08 & 12.79 \\
\hline
\end{tabular}

* Oxygen content is by difference.

\subsection{Experimental conditions}

A thermogravimetry (TG) instrument (Seiko co., Ltd. 7300, Japan) was employed to measure the ignition temperature. As schematically shown in the Figure 1, a certain amount of the sample was placed in a platinum crucible and heated until a fire was generated. A mixture of $\mathrm{O}_{2}$ and $\mathrm{N}_{2}$ was introduced into the thermogravimeter as the carrier-gas at a particular flow rate to maintain the $\mathrm{O}_{2}$ $\mathrm{N}_{2}$ atmosphere. Oxygen concentration, carrier-gas flow rate, heating rate, and sample amount were varied to study their impact on the ignition temperature.

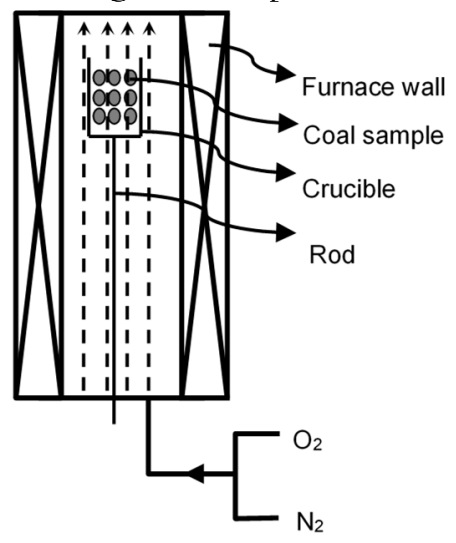

Fig1. Schematic diagram of the experimental apparatus.

\subsection{Determination of ignition temperature}

The on-set method [11-12] is not suitable for low-rank coals due to poor reproducibility of results. We defined the temperature corresponding to the point that has maximum slope variation and prior to the combustion peak on the DTG curve as the tested ignition temperature. The method avoided the influence of TG curve's shape and the reproducibility of results was considerably improved (Supporting Information 1).

\section{Results and discussion}

\subsection{Effect of experimental conditions on ignition temperature}

DLT-52 was used as a typical sample. The ignition temperature was tested under different conditions: $\mathrm{O}_{2}$ concentration ranged from 20 to $100 \%$, carrier-gas flow rate was varied from 50 to $250 \mathrm{~mL} / \mathrm{min}$, the heating rate was varied from 20 to $60{ }^{\circ} \mathrm{C} / \mathrm{min}$, and sample amount was varied from 5 to $16.5 \mathrm{mg}$.
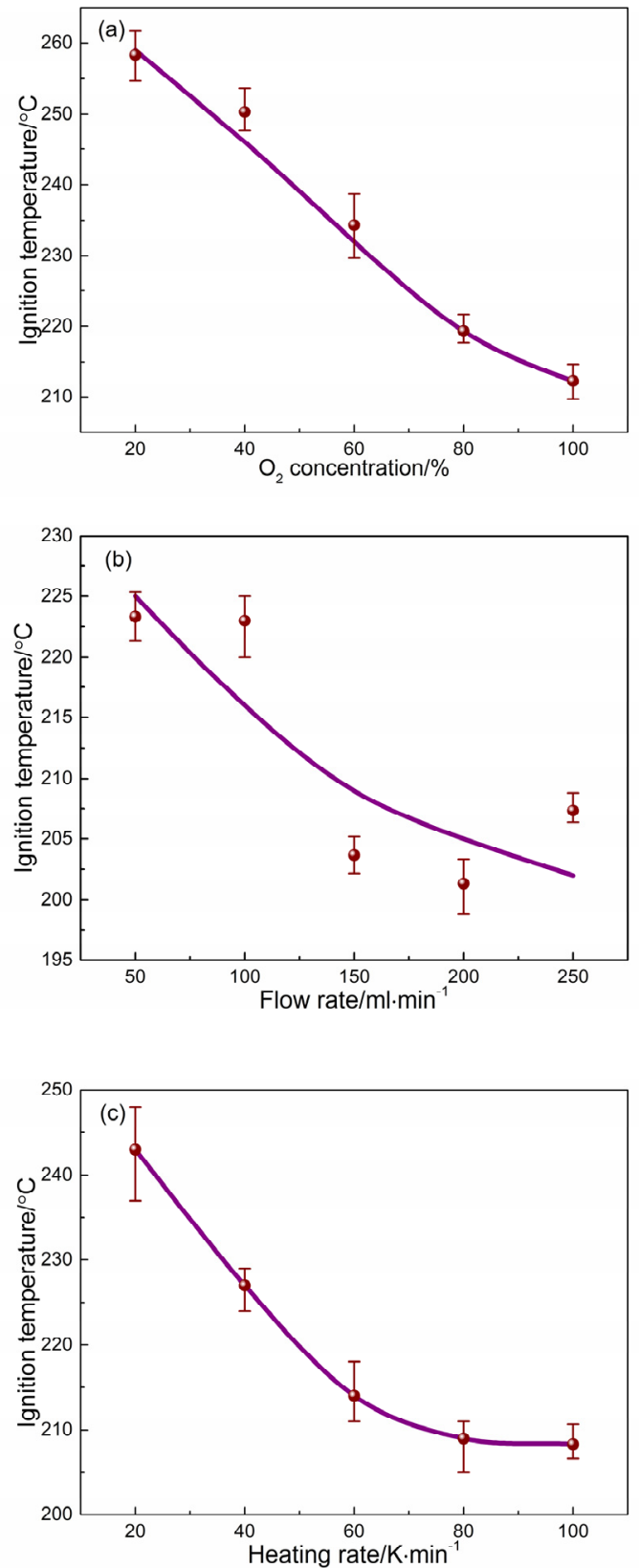


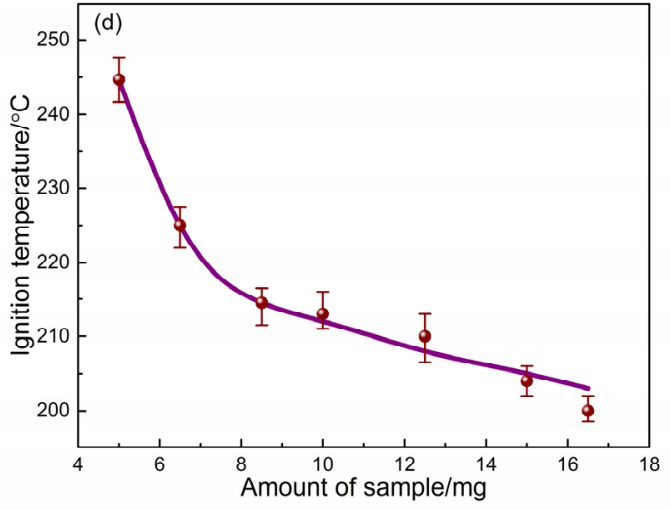

Fig2. Influence of various conditions on ignition temperatures. (a) $\mathrm{O}_{2}$ concentration, (b) Carrier-gas flow rate, (c) Heating rate, (d) Amount of sample

\subsubsection{Effect of $\mathrm{O}_{2}$ concentration}

The other conditions in Figure 2(a) are $10 \mathrm{mg}$ samples, heating rate of $20{ }^{\circ} \mathrm{C} / \mathrm{min}$ and flow rate of $100 \mathrm{~mL} / \mathrm{min}$. When oxygen concentration is $20 \%$, the ignition temperature reaches to $260{ }^{\circ} \mathrm{C}$, when pure oxygen is used, the ignition temperature drops to $212^{\circ} \mathrm{C}$. The difference between the maximum and the minimum temperature is $50{ }^{\circ} \mathrm{C}$. With the increase in oxygen concentration, it can be inferred that the reaction rate of coal and oxygen will accelerate causing an increase in the heat release rate, that will lead to the ignition point of coal reaching earlier resulting in a decrease in the tested ignition temperature.

\subsubsection{Effect of oxygen flow rate}

The other conditions in Figure 2(b) are a heating rate of $20{ }^{\circ} \mathrm{C} / \mathrm{min}$ for a sample amount of $10 \mathrm{mg}$. As the flow rate increased, the ignition temperature decreased. The oxygen flow rate impact the diffusion of the external oxygen to the coal surface. With an increase in the flow rate, the external diffusion is reduced, and the reaction rate is increased, lowering the tested ignition temperature [13].

The range of the tested ignition temperature was $20^{\circ} \mathrm{C}$ as the flow rate varied from 50 to $250 \mathrm{~mL} / \mathrm{min}$. When the flow rate was greater than $150 \mathrm{~mL} / \mathrm{min}$, the range was less than $2{ }^{\circ} \mathrm{C}$, indicating that the influence of the external diffusion is minimized. Extremely high flow rates may disturb the thermos-balance or take away more heat from the system. This causes new challenges, such as an increase in the ignition temperature upon the increase of the flow rate to $250 \mathrm{~mL} / \mathrm{min}$.

\subsubsection{Effect of heating rate}

The other conditions in Figure 2(c) are an $\mathrm{O}_{2}$ flow rate of $200 \mathrm{~mL} / \mathrm{min}$ for a sample amount of $10 \mathrm{mg}$. The tested ignition temperature decreases with an increase in the heating rate. When the heating rate is $20{ }^{\circ} \mathrm{C} / \mathrm{min}$, the ignition temperature is $243{ }^{\circ} \mathrm{C}$, which then reduces to $208^{\circ} \mathrm{C}$ upon an increase of the heating rate to $100{ }^{\circ} \mathrm{C} / \mathrm{min}$, over the $35{ }^{\circ} \mathrm{C}$ range. The change in the ignition temperature is much larger when the heating rate varying from 20 to $60{ }^{\circ} \mathrm{C} / \mathrm{min}$ than it varying from 60 to $100{ }^{\circ} \mathrm{C}$ $/ \mathrm{min}$, indicating that the sensitivity is minimized when the heating rate is greater than $60^{\circ} \mathrm{C} / \mathrm{min}$.

\subsubsection{Effect of sample amount}

The other conditions in Figure 2(d) are a flow rate of 200 $\mathrm{mL} / \mathrm{min}$ and a heating rate of $60^{\circ} \mathrm{C} / \mathrm{min}$. The effect of the coal sample amount and the tested ignition temperature decreased as the sample amount increased. Variations in the sample amounts cause variations of the sample cylinder height in a special crucible. With an increase in the sample height, the heat transfer from the surface to the interior of the sample stack becomes more difficult, leading to a decrease in the tested ignition temperature.

Apparently, when the amount of sample increased from 5 to $10 \mathrm{mg}$, the ignition temperature reduced by $35^{\circ} \mathrm{C}$, and when the sample amount increased from 10 to $16.6 \mathrm{mg}$, the ignition temperature reduced by only $15^{\circ} \mathrm{C}$.

$10 \mathrm{mg}$ of the sample with pure oxygen at a flow rate of $200 \mathrm{~mL} / \mathrm{min}$ and a heating rate of $60{ }^{\circ} \mathrm{C} / \mathrm{min}$ were chose as the optimal conditions. The ignition temperatures of 15 low-rank coals were measured by these conditions, and the average error was reduced within $\pm 0.5^{\circ} \mathrm{C}$ in most cases (Supporting Information 2) .

\subsection{Effect of coal chemical properties on ignition temperature}
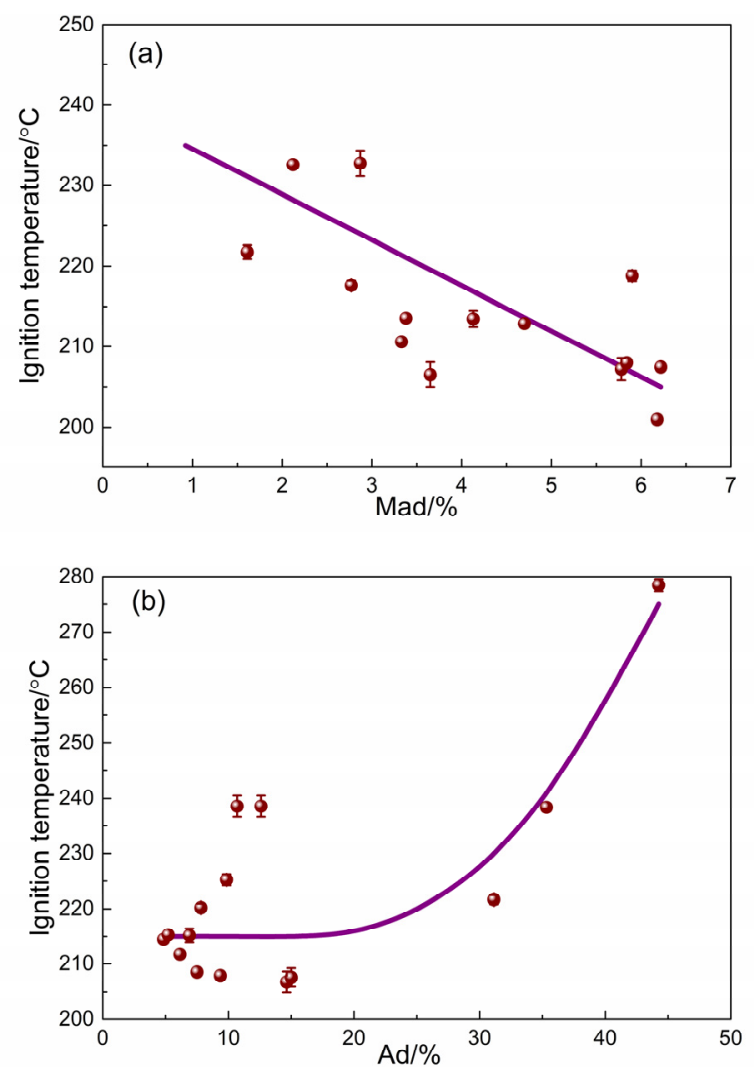

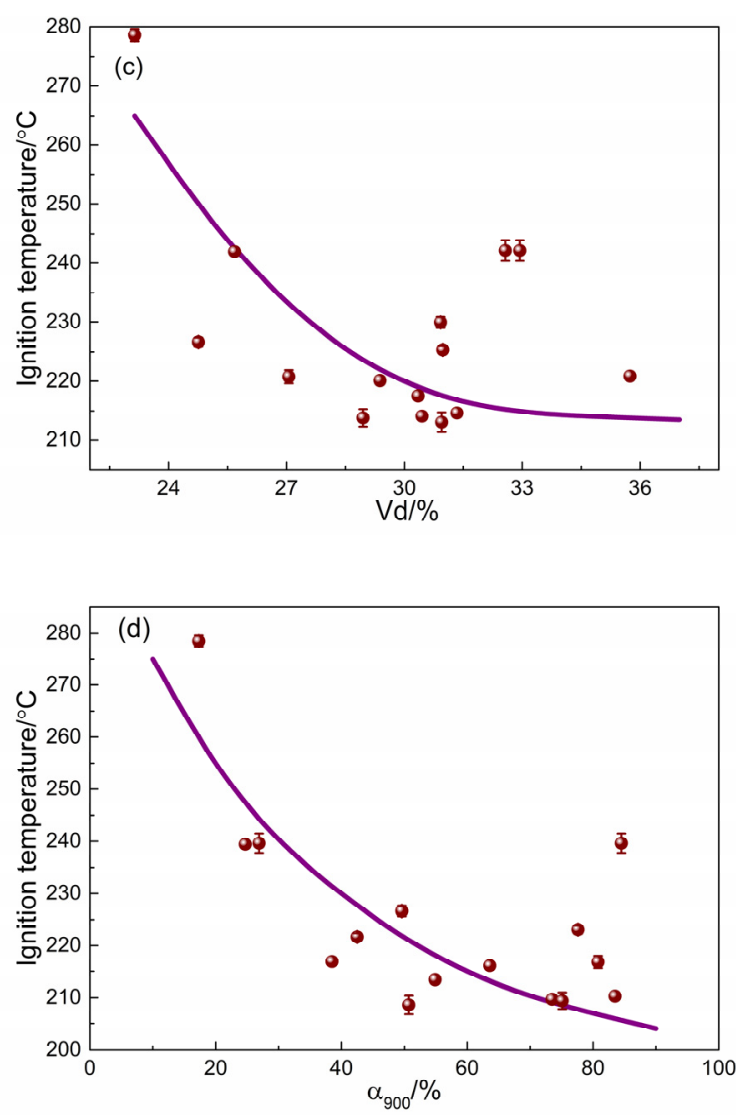

Fig3. Ignition temperature corresponding to the properties of the coal sample.

(a) Moisture content, (b) Ash content, (c) Volatile content, (d) Reduction rate of $\mathrm{CO}_{2}$ by coal at $900{ }^{\circ} \mathrm{C}\left(\alpha_{900}\right)$

\subsubsection{Effect of moisture}

To minimize the influence of the moisture content, the samples were dried before testing and dried gas was used in this work. In Figure 3(a), a relationship between the moisture content (air-dried basis) and ignition temperature was found that the ignition temperature decreased as the air-dried moisture increased. The residual water in the coal under dried air is related to the number of pores, and higher moisture indicates a more developed pore system. The characteristics of pore in coal are indicative of its age. Therefore, the presence of higher moisture indicates that the coal is younger, which have more active groups and may have a significant influence on its ignition temperature.

\subsubsection{Effect of ash content}

The results presented in Figure 3(b) show that the higher the ash content, the higher the ignition temperature. The higher ash in coal, the combustible components to be more likely wrapped in ash that acts as flame retardants [14]. In addition, higher ash content reduces the concentrations of the flammable components that further reduces the rate of the oxidation reaction. BD- 8 has a high ash of $45 \%$, and its ignition temperature reaches to $280^{\circ} \mathrm{C}$, which is clearly higher than that of the other coals. However, when the ash content was less than $20 \%$, the ignition temperatures presented no regular change, indicating the involvement of more complex factors impact the ignition temperatures of the low-rank coal.

\subsubsection{Effect of volatile content}

Figure 3(c) shows that the higher the volatile content, the lower the ignition temperature. To a certain extent, the content of the volatile reflects the content of the active components, which oppositely affects the ignition temperature compare with the flame-retardant effect of ash. Higher volatility leads to a higher coal-oxygen reaction rate and easy ignition.

When the volatile content is higher than $30 \%$, the influence on the ignition temperatures becomes insignificant. It indicates that more complex factors that exert influence on the ignition temperatures need be considered.

\subsubsection{Effect of chemical reactivity}

The reduction degree of $\mathrm{CO}_{2}$ by coal at $900{ }^{\circ} \mathrm{C}\left(\alpha_{900}\right)$ was used as the value that presents the chemical reactivity of the low-rank coal. Figure 3(d) exhibits that the ignition temperature decreases with the increase in $\alpha_{900}$. The strong correlation between chemical reactivity and the ignition temperature indicates the importance of this parameter in evaluating ignition temperature tendency. Reduction degree of $\mathrm{CO}_{2}$ by coal is a parameter commonly used for coal gasification and combustion in industry. Higher chemical reactivity is indicative of lower activation energy of ignition, therefore, the ignition could occur at a lower temperature.

In summary, $\mathrm{O}_{2}$ concentration and flow rate were related to chemical kinetics, heating rate and sample amount were related to heat conduction, and coal properties were related to the thermodynamics of the process. The ignition process is complexly affected by these factors.

\subsection{Ignition mechanism and prediction of spontaneous combustion potential}

\subsubsection{Thermogravimetric behavior around ignition moment}

To probe the phenomena that prevail prior to ignition, we focused on the changes on the weight and heat flow online by thermogravimetric analysis. In Figure 4, curves (a), (b) and (c) indicate the typical weight changes of DLT-52 under optimized conditions by TG, DTG, and differential thermal analysis (DTA). 


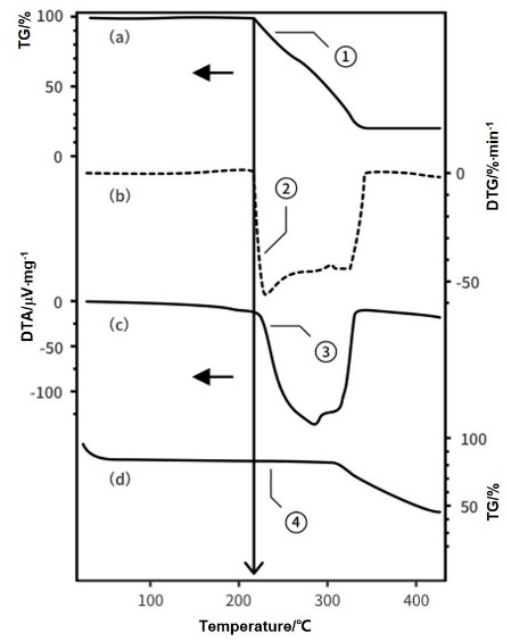

Fig4. Behavior of low-rank coal as per thermogravimetric analyses. (a) TG curve, (b) DTG curve, (c) DTA curve, (d) TG curve in $\mathrm{N}_{2}$ atmosphere.

The TG plot shows a typical weight loss trend, which indicated the initiation of the weight loss at the location marked (1) at around $230{ }^{\circ} \mathrm{C}$; the loss ended at approximately $350{ }^{\circ} \mathrm{C}$ where the plot became flat again. The weight loss can be described further by the DTG plot. At the location marked (2), the loss rate became higher within a very short time at around $230{ }^{\circ} \mathrm{C}$, indicating that the weight loss occurred suddenly. The change in the DAT plot corresponding to the weight loss temperature (Location (3) testified that the weight loss is an exothermic process. They are typical ignition process that ignition happens at an ignition temperature recorded by thermogravimetric.

However, a careful comparison of the curves revealed that the evident change in DTG is prior to the evident change in TG, which is a key evidence that at the point of ignition, the weight loss is not evident, implying that only a small amount of substance initially undergoes ignition. Therefore, this result clearly indicates that a small amount of substance exists in the coal that is more active than the rest of the sample and is the origin of the ignition. It is considerably different from the theory of homogeneous ignition, wherein the volatiles in the coal firstly react with oxygen in the gas phase [15-18]. The TG plot of the same sample in $\mathrm{N}_{2}$ under the same heating conditions was compared with the TG plot; no weight loss was detected in coal around the ignition temperature (Location (4) in Curve (d)).

\subsubsection{Heterogeneous ignition model of the coal surface}

A low-rank coal particle model was illustrated in Figure 5(a). A small amount of active species heterogeneously covers the surface of the coal particles (assumed as spherical particles). The species could be the side chains with active chemical structures, which have different physical and chemical properties from the coal particles, and can be considered as another phase that adheres to the coal particle surface.

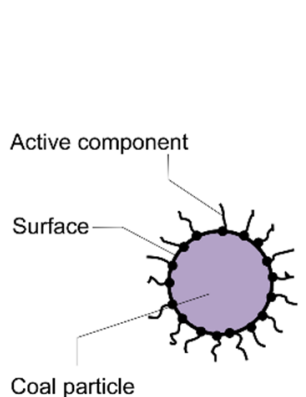

(a)

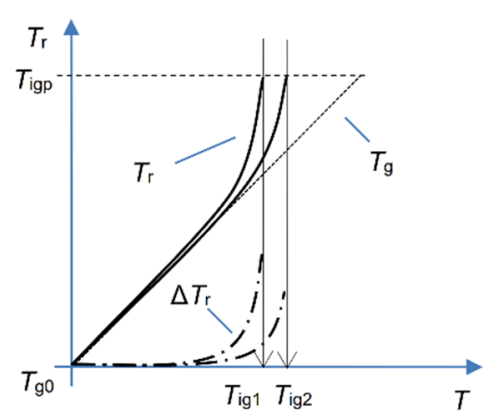

(b)
Fig5. Model for the heterogeneous ignition mechanism of lowrank coal. (a) Particle model demonstrating the heterogeneous distribution of active ignition matter over the coal surface, (b) Temperature profiles of the ignition matter before ignition.

In a thermogravimetric test, the tested temperature $(T)$ is controlled by employing a heating rate that equals the temperature of the carrier gas $\left(T_{g}\right)$ and is expressed by Eq. (1).

$$
\mathrm{T}=\mathrm{T}_{\mathrm{g}}
$$

In the heating process, the heat was transferred to the coal by the carrier gas. $T_{\mathrm{g}}$ is the temperature of the active species $\left(T_{\mathrm{r}}\right)$ on the surface. The case of no activity is depicted by a straight dotted line shown in Figure 5(b). After the active species react with oxygen, reaction heat is generated and transferred to coal particles. In the nonequilibrium state discussed above, the time for the transfer of the reaction heat to the coal particles is limited, then the accumulated heat increases the temperature of the active species. This increment in $T_{\mathrm{r}}\left(\Delta T_{\mathrm{r}}\right)$ is described by the dotdash line in Figure 5(b). Therefore, $T \mathrm{r}$ is the sum of $T_{\mathrm{g}}$ and $\Delta T_{\mathrm{r}}$, depicted by the solid line shown in Figure 5(b), and is expressed by Eq. (2).

$$
\mathrm{T}_{\mathrm{r}}=\mathrm{T}_{\mathrm{g}}+\Delta \mathrm{T}_{\mathrm{r}}=\mathrm{T}+\Delta \mathrm{T}_{\mathrm{r}}
$$

Once $\operatorname{Tr}$ reaches the temperature of the ignition point ( $T_{\text {igp }}$, a constant), the active species ignite and then induce the subsequent ignition of coal particles. $T$ at this moment is the tested ignition temperature $T_{\mathrm{ig}}$ (expressed by Eq. (3)). Different conditions have impact on the heat generation and heat loss, resulting in different $\Delta T_{\mathrm{r}}$ profiles before ignition, and then the value of $T_{\text {ig }}$ also differ.

$$
\mathrm{T}_{\text {igp }}=\mathrm{T}_{\mathrm{ig}}+\Delta \mathrm{T}_{\mathrm{r}}
$$

The concentration of the active species is $C_{\mathrm{r}}$, concentration of oxygen is $C_{\mathrm{O}_{2}}$, coal-oxygen reaction is a first-order reaction with $k$ as the apparent rate constant, and reaction enthalpy is $\Delta H$. The heat generation rate is represented by $k C_{\mathrm{r}} C_{\mathrm{O}_{2}} \Delta H$. When oxygen concentration is increased, $C_{\mathrm{O}_{2}}$ increases. Further, with an increase in flow rate, the collision probability between $\mathrm{O}_{2}$ and coal increases. These lead to an increase in $k$, that enhances the heat generation rate. Thus, $\Delta T_{\mathrm{r}}$ becomes larger at the same heating rate, and $T_{\text {ig }}$ decreases as observed in Figure 2(a) and Figure 2(b). When the heating rate increases, the heat generation rate also increases and the heat transfer time reduces, which cause increase of $\Delta T_{\mathrm{r}}$, and then $T_{\mathrm{ig}}$ decreases as observed in Figure 2(c). When the heating 
rate, gas flow rate, and oxygen concentration are fixed, thermal conductivity of coal becomes the factor influencing $\Delta T_{\mathrm{r} \text {. }}$. Higher volumes of the sample cause greater heat accumulation, leading to lower ignition temperatures as shown in Figure 2(d). In summary, the effects of oxygen concentration and carrier-gas flow rate ascribe to the oxygen-coal reaction kinetics, and the effects of heating rate and amount of sample ascribe to the heat conduction process.

When the ash content in the coal increases, the concentration of the active species decreases and the heat generation rate is reduced. The ignition temperature is then elevated as described in Figures 3(b). The effect of volatiles on the ignition temperature shown in Figure 3(c) similarly can be explained.

To sum up, the ignition mechanism is very useful for understanding the special ignition behavior of low-rank coal and is valuable for managing the safety aspects of coal stacks to preventing their spontaneous combustion.

\subsubsection{Prediction of spontaneous combustion potential}

The inherent properties including $A_{\mathrm{d}}, V_{\mathrm{d}}$, and $\alpha_{900}$ are associated with the complexity of the analyzed results. Using a statistical software (JMP), we fitted the data to a formula which is expressed by the following equation and is based on the ignition temperatures of the 15 coals.

$$
T_{\mathrm{ig}}=290+0.54 e^{2.27 \frac{A_{\mathrm{d}}}{V_{\mathrm{d}}}}-19 \ln \left(\alpha_{900}\right)
$$

where $T_{\text {ig }}$ is the ignition temperature $\left({ }^{\circ} \mathrm{C}\right), A_{\mathrm{d}}$ is the dry basis ash content (wt\%), $V_{\mathrm{d}}$ is the dry volatile content (wt $\%$ ), and $\alpha_{900}$ is the reduction degree of $\mathrm{CO}_{2}$ by coal at $900^{\circ} \mathrm{C}$.

The comparison of residuals between the predicted and experimental values appears to present a good correlation $\left(R^{2}=0.91\right)$; the probability of correct prediction is 0.95 when the confidence interval of error is within $\pm 11.0^{\circ} \mathrm{C}$, and the probability could be 0.997 if the confidence interval allowed is within $\pm 14.4{ }^{\circ} \mathrm{C}$ (Supporting Information 4).

\section{Conclusion}

Low-rank coal is likely to become the main energy resource in the future, especially for China. The use of low-rank coal, however, causes challenges in terms of its spontaneous combustion. In this work, the influence factors including the test conditions in thermal gravimetric analyzer and coal properties were studied. The results demonstrated that the spontaneous combustion of lowrank coal was complexly affected by those factors. Combined with the typical behavior in thermal gravimetric analyzer, a heterogeneous ignition model was proposed for low-rank coal. Based on the presence of a small amount of active species that heterogeneously adhere to the surface of the coal particles, it revealed that the active matter, rather than coal particles, firstly ignites. Further, the change tendency of ignition temperature was well explained by three Equations deduced from the heterogeneous mechanism. In addition, an empirical formula to predict the ignition temperature using ash content, volatile content, and reduction reactivity of coal was established.

In a word, this paper provided a new understanding of the special ignition performance of low-rank coal, which will aid in safe and effective management of coal stacks in terms of preventing their spontaneous combustion.

\section{Supplementary Material}

\section{SI1: Method for determining the measured ignition temperature}

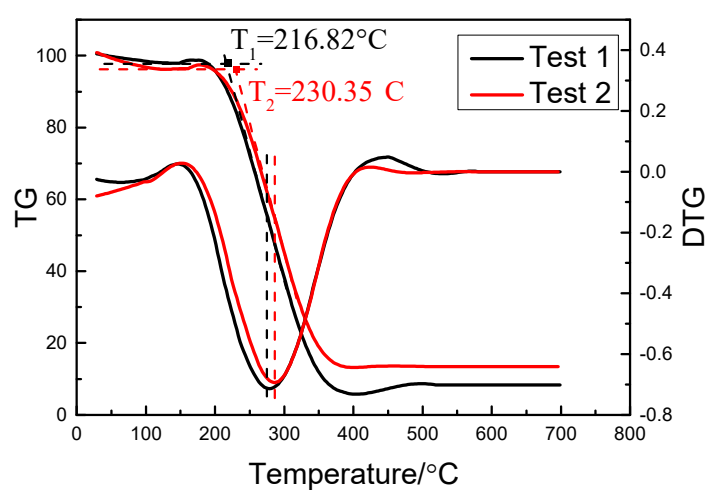

Figure S1. TG-DTG tangent method for determination of ignition temperature.

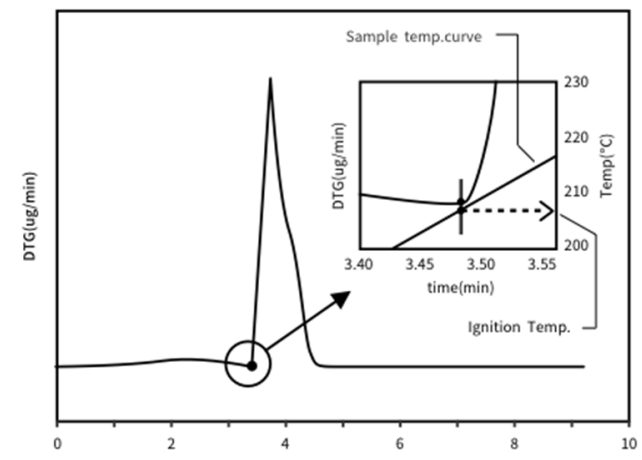

Figure S2. Schematic diagram of determination method of ignition temperature.

Table S1. Ignition temperature of YJL-52 measured with

\begin{tabular}{|c|c|c|c|}
\hline Method & Test1 & Test2 & Range \\
\hline TG-DTG tangent method & 216.82 & 230.35 & 13.53 \\
\hline $\begin{array}{c}\text { DTG inflection point } \\
\text { method }\end{array}$ & 227.6 & 225.5 & 2.1 \\
\hline
\end{tabular}

The details of TG-DTG tangent method is showed in Figure S1. The TG curve and DTG curve of YJL-52 under the same experiment conditions in test 1 and test 2 are showed as red line and black line. Apparently, as shown in Table S1, two groups curves are slightly different in shape, resulting in a difference of $13.53{ }^{\circ} \mathrm{C}$ in the ignition temperature.

As shown in Figure S2, the temperature corresponding to the maximum slope point on the DTG curve is defined 
as the ignition temperature. The definition avoids the effect of curve shape, and the measuring range is reduced to $2.1{ }^{\circ} \mathrm{C}$, which exhibits good repeatability.

\section{S12: Validation of optimized operation conditions}

Table S2. Ignition temperature of 15 low rank coals measured with optimized conditions.

\begin{tabular}{cccccc}
\hline Sample & Average & Range & Sample & Average & Range \\
\hline BD-8 & 278.5 & \pm 2.2 & SSLT-4 & 209.65 & \pm 0.5 \\
BET-22 & 216.1 & \pm 0.2 & SSLT-5 & 210.35 & \pm 0.1 \\
BET-42 & 208.6 & \pm 3.6 & SW-12 & 216.8 & \pm 2.4 \\
DLT-52 & 213.4 & \pm 0.4 & WL1-31 & 223.05 & \pm 1.7 \\
HYC-4 & 239.4 & \pm 0.4 & WL1-42 & 209.35 & \pm 3.1 \\
HYC-6 & 239.55 & \pm 3.9 & YJL-43 & 221.65 & \pm 1.3 \\
JJ-31 & 216.9 & \pm 0.2 & YJL-52 & 226.55 & \pm 2.1 \\
SSLT-3 & 201.95 & \pm 0.1 & & & \\
\hline
\end{tabular}

SI3: Reduction degree of $\mathrm{CO}_{2}$ by coal at $900{ }^{\circ} \mathrm{C}$

Table S3. Reduction rate of $\mathrm{CO}_{2}$ by coals at $900{ }^{\circ} \mathrm{C}$.

\begin{tabular}{cccccc}
\hline Sample & $\alpha 900$ & Sample & $\alpha 900$ & Sample & $\alpha 900$ \\
\hline BD-8 & 17.3 & HYC-6 & 26.9 & SW-12 & 80.8 \\
BET-22 & 63.6 & JJ-31 & 38.5 & WL1-31 & 77.6 \\
BET-42 & 50.7 & SSLT-3 & 84.5 & WL1-42 & 75.1 \\
DLT-52 & 54.9 & SSLT-4 & 73.5 & YJL-43 & 42.5 \\
HYC-4 & 24.7 & SSLT-5 & 83.5 & YJL-52 & 49.6 \\
\hline
\end{tabular}

\section{S14: The reliability of ignition temperature prediction formula}

As shown in Figure S3, it appears a good correlation $\left(\mathrm{R}^{2}=0.91\right)$ between the predicted value and the measured value, and the residual is a normal distribution, which indicate the reliability of the prediction. The eigenvalues of the normal distribution curve are $\mu=0$ and $\sigma=5.6$, which means that the confidence interval of the prediction error is $\pm 11.0^{\circ} \mathrm{C}$ when the probability of correct prediction is 0.95 , and the confidence interval of the prediction error is $\pm 14.4{ }^{\circ} \mathrm{C}$ when the probability of correct prediction is 0.997. This prediction formula can be used to rapidly estimate the ignition temperature of low rank coal, thus helping to evaluate the tendency of spontaneous combustion.

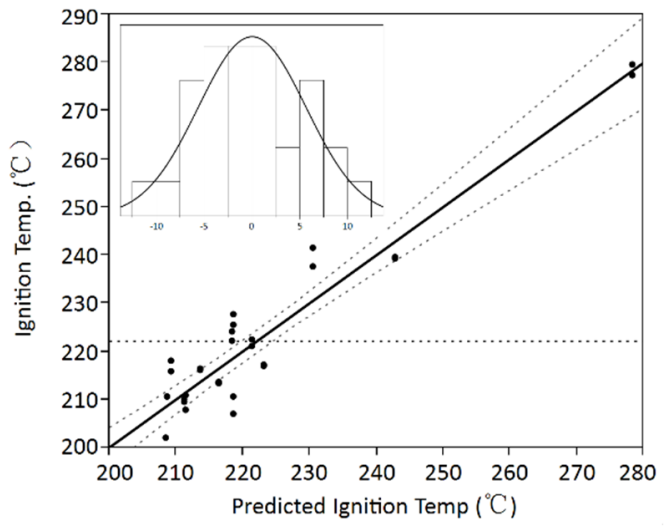

Figure S3. Residual analysis of predicted and experimental values.

\section{Acknowledgments}

This work was supported by grants from the National Natural Science Foundation of China [Grant No. 21606083, and the Fundamental Research Funds for the Central Universities [Grant No, 2016MS017].

\section{References}

1. H.Q. Zhu, Z.Y. Song, B. Tan, Y.Z. Hao, J. Loss Prevent. Proc 26, 236 (2013)

2. H.H. Wang, B.Z. Dlugogorski, E.M. Kennedy, Prog. Energy. Combust. Sci 29, 487 (2003)

3. J. Cheng, X. Wang, T.T. Si, F. Zhou, J.H. Zhou, K.F. Cen, Fuel 173, 230 (2016)

4. B.B. Beamish, M.A. Barakat, J.D.S. George, Int. J. Coal Geol 45, 217 (2001)

5. X. Cui, X.X. Zhang, M. Yang, Y.H. Feng, H.Y. Gao, W.B. Luo, J. Therm. Anal. Calorim 113, 693 (2013)

6. J.F. Wang, Y.L. Zhang, S. Xue, J.M. Wu, Y.B. Tang, L.P. Chang, Fuel. Process. Technol 179, 60 (2018)

7. T.F. Wall, R.P. Gupta, V.S. Gururajan, D.K. Zhang, Fuel 70, 1011 (1991)

8. Y. Chen, S. Mori, W.P. Pan, Thermochim. Acta 275, 149 (1996)

9. C.L. Sun, M.Y. Zhang, Combust. Flame 115, 267 (1998)

10. Q. Xu, S.Q. Yang, J.W. Cai, B.Z. Zhou, Y.N. Xin, Process. Saf. Environ. Prot 118, 195 (2018)

11. M. Cloke, E. Lester, W. Gibb, Fuel 76, 1257 (1997)

12. J.R. Wang, C.B. Deng, Y.F. Shan, L. Hong, W.D. Lu, Journal of China Coal Society 33, 47 (2008)

13. R. Jovanovic, A. Milewska, B. Swiatkowski, A. Goanta, H. Spliethoff, Int. J. Heat Mass Tranf 54, 921 (2011)

14. B.J. Yi, L.Q. Zhang, F. Huang, Z.J. Xia, Z.H. Mao, J.W. Ding, C.G. Zheng, Energy. Convers. Manag 103, 439 (2015)

15. A. Richter, M. Vascellari, P.A. Nikrityuk, C. Hasse, Fuel. Process. Technol 144, 95 (2016)

16. J.B. Howard, R.H. Essenhigh, Symp. (Int.) Combust 11, 399 (1967)

17. T. Asotani, T. Yamashita, H. Tominaga, Y. Uesugi, Y. Itaya, S. Mori, Fuel 87, 482 (2008)

18. R.H. Essenhigh, J. Csaba, Symp. (Int.) Combust 9, 111 (1963) 